\title{
Erratum to: Volcanic Glass and Iron Nails: Networks of Exchange and Material Entanglements at Late Prehispanic and Early Colonial Achiutla, Oaxaca, Mexico
}

\author{
Jamie E. Forde ${ }^{1}$
}

Published online: 10 November 2016

(C) Springer Science+Business Media New York 2016

\section{Erratum to: Int J Histor Archaeol (2016) DOI 10.1007/s10761-016-0368-z}

In the above-mentioned article, occurrences of "Terrace 10" were written incorrectly as "Terrace ten" throughout the article. The original article was corrected.

Jamie E. Forde

Jamie.Forde@gmail.com

1 University of Pennsylvania, Philadelphia, PA, USA 